\title{
Embryochemische Untersuchungen.
}

\author{
Von
}

P. A. Levene.

(Aus dem «Saranac Research Laboratory», Dr. E. L. Trudeau, Director.)

(Der Redaction zugegangen am 28. Januar 1902.)

Die chemischen Umwandlungen, welche sich in thierischen Embryonen vollziehen, sind bisher verhältnissmässig wenig untersucht worden. In einer sehr wichtigen Arbeit auf diesem Gebiete hat A. Kossel festgestellt, dass die Nucleine in bebrüteten und unbebrüteten Eiern eine verschiedene Zusammensetzung hatten. Die echten Nucleine kommen nur in den bebrüteten Eiern vor, in den anderen konnte Kossel nur Paranucleine finden. Ferner hat Tichomiroff im Laboratorium von Prof. Kossel die chemischen Processe bei der Entwicklung der Insecten-Embryonen einem näheren Studium unterworfen und endlich liegt noch eine Publication von Leo Liebermann über dasselbe Thema vor. In allen diesen Arbeiten wurde aber den stickstoff haltigen Zwischenprodukten verhältnissmässig wenig Aufmerksamkeit gewidmet.

Im Jahre 1899 habe ich die Resultate meiner embryochemischen Untersuchungen bebrüteter Fischeier mitgetheilt. Ich habe dann versucht, die Verschiedenheiten im Gehalte an Eiweisskörpern und an anderen stickstoffhaltigen Substanzen in bebrüteten Eiern von verschiedenem Alter festzustellen. Die Substanzen nicht eiweissartiger Natur wurden nach ihrem Verhalten $\mathrm{zu}$ Phosphorwolframräure in fällbare und nicht fällbare eingetheilt.

Meine Befunde können kurz in folgender Tabelle zusammengestellt werden. 


\begin{tabular}{|c|c|c|c|c|}
\hline & \multicolumn{4}{|c|}{ Procente des Gesammtstickstoffs } \\
\hline & $\underset{\substack{\text { Unbebrütete } \\
\text { Eier }}}{ }$ & $\mid \begin{array}{l}\text { Bebrütete,24 } \\
\text { Stunden alt }\end{array}$ & $\begin{array}{l}\text { Bebrütete, } \\
10 \text { Tage alt }\end{array}$ & $\begin{array}{l}\text { Bebrutete } \\
19 \text { Tage alt }\end{array}$ \\
\hline $\begin{array}{l}\text { Stickstoff der durch Phosphor- } \\
\text { wolframsäure nicht fällbaren }\end{array}$ & & & & \\
\hline $\begin{array}{l}\text { Substanzen } \cdot \cdot \cdot \cdot \cdot \cdot \cdot \\
\text { Stickstoff der durch Phosphor- } \\
\text { wolframsäure fällbaren Sub- } \\
\text { stanzen nicht eiweissartiger }\end{array}$ & $21,10 \%$ & $21,37 \%$ & $22,72 \%$ & - \\
\hline Natur. . . . . . . & $12,07 》$ & $25,10 \gg$ & 12,48 & $28,25 \%$ \\
\hline Stickstoff der Eiweisskörper . & 66,00 & 53,57 & 64,79 > & 71,84 » \\
\hline
\end{tabular}

Weitere Untersuchungen über die Natur der verschiedenen stickstoffhaltigen Substanzen wurden dann nicht unternommen. Erst im letzten Herbst hatte ich Gelegenheit, die Arbeit in dieser Richtung fortzusetzen.

Vorläufig habe ich mich wegen Mangels an Material mit der Frage des Vorkommens von Monoaminosäuren in den bebrüteten Eiern begnügt. Für diese Arbeit wurden Hühnereier benutzt, da es mir unmöglich war, eine genügende Quantität von Fischeiern zu beschaffen.

Für meine Versuche verwendete ich zum Theil bebrütete Eier, die 24 Stunden alt, und zum Theil solche, die 7 Tage alt waren. Nur diejenigen Eier, welche eine Entwicklung des Embryos zeigten, und von den 7 tägigen nur solche, die lebendige Embryonen enthielten, wurden für die Untersuchung benutzt.

Das Eigelb wurde von dem Weissen mechanisch getrennt. Bei den 7 tägigen war dies jedoch nicht vollkommen ausführbar. Die verschiedenen Portionen wurden in 95\% oigen Alkohol gebracht, der Rückstand vom abfiltrirten Alkohol mit Wasser verrieben, ein gleiches Volumen 95\%iger Alkohol hinzugefügt und die Flüssigkeit wieder vom Rückstande abfiltrirt. Von den vereinigten Filtraten wurde der Alkohol auf dem Wasserbade bei niederer Temperatur verdunstet, zu der alkoholfreien Flüssigkeit wieder das mehrfache Volumen 95\% iger Alkohol zugefügt und der Alkohol auf dem Wasserbade verjagt. Der Rückstand der 24 stündigen Eier, welcher keine Beimischung des Eier-

Hoppe-Seyler's Zeitschrift f. physiol. Chemie. XXXV. 
albumins enthalten hatte, erwies sich dann als eiweissfrei; die 7 tägigen dagegen enthielten noch Eiweiss, und zwar ein Glukoproteid, welches erst durch weitere Fällung mit Alkohol entfernt werden musste.

Die eiweissfreien Rückstände wurden nun in absolutem Alkohol aufgenommen und nach E. Fischer's Verfahren mit trockener Salzsäure verestert. Der Alkohol wurde bei etwa $10 \mathrm{~mm}$. Druck verdunstet und die Veresterung mit Alkohol und Salzsäure wiederholt. Dieses Verfahren wiederholt wich noch zweimal. Die freien Ester wurden jetzt aus den Chlorhydraten ebenfalls nach dem Verfahren von E. Fischer dargestellt, getrocknet und bei $8-9 \mathrm{~mm}$. Druck fractionirt. Nur die Fraction unter $75^{\circ} \mathrm{C}$. ging ohne Zersetzung über. Der andere Theil fractionirte bei $75-120^{\circ} \mathrm{C}$, , aber immer unter theilweiser Zersetzung.

Die erste Fraction wurde durch dreistündiges Kochen mit Wasser in einem Kolben mit Rückflusskühler verseift, die Reactionsflüssigkeit durch Kochen mit Thierkohle entfärbt, auf dem Wasserbade verdunstet, der. Rückstand mit Alkohol ausgekocht und der alkoholunlösliche Theil (getrocknet im Luftbade bei $108^{\circ}$ G.) analysirt.

Der Rückstand der 24stündigen Eier gab die folgenden Resultate:

$0,1209 \mathrm{~g}$ Substanz gaben bei Verbrennung $0,2195 \mathrm{~g} \mathrm{CO}_{2}$ und $0,0935 \mathrm{~g} \mathrm{H}_{2} \mathrm{O}$.

$0,103 \mathrm{~g}$ Substanz gaben bei Verbrennung $12,4 \mathrm{ccm}$. Stickstoff bei B. $=711$ und $\mathrm{T} .=16^{\circ} \mathrm{C}$.

Der Rückstand der 7 tägigen Eier gab die folgenden Resultate:

$0,0995 \mathrm{~g}$ Substanz gaben bei Verbrennung $0,1771 \mathrm{~g} \mathrm{CO}_{2}$ und $0,0754 \mathrm{~g} \mathrm{H}_{2} \mathrm{O}$. $14,30 \mathrm{ccm}$.

$0,1287 \mathrm{~g}$ Substanz bei B. $=718$ und T. $=9^{\circ}$ C. gaben Stickstoff

Für $\mathrm{C}_{4} \mathrm{H}_{8} \mathrm{NO}_{2}+\mathrm{C}_{5} \mathrm{H}_{11} \mathrm{NO}_{2}$

Berechnet:

Gefunden:

$\begin{array}{lcc}\mathrm{C}=49,09 \% & \text { in } 24 \text { stündigen Eiern } & \text { in 7tägigen } \\ \mathrm{H}=9,09 \% & 49,58 \% & 48,52 \% \\ \mathrm{~N}=12,70 \% & 8,59 » & 8,41 \% \\ & 13,10 » & 12,46 \%\end{array}$


Aus diesen Befunden kann man mit Sicherheit schliessen, dass bebrütete Eier Monoaminosäuren enthalten. Es ist auch wahrscheinlich, dass die untersuchten Präparate aus einem äquimolekularen Gemische von Monoaminobuttersäure und Monoaminovaleriansäure bestanden.

Ich hoffe im Frühjahre Gelegenheit zur Untersuchung unbebrüteter Eier zu haben und werde dann meine embryochemischen Studien fortsetzen.

\section{Litteratur.}

A. Kossel, Zeitschr. f. physiol. Chem., Bd. IX, S. 578.

Levene, Arch. of Neurology, Bd. 2, S. 1-14, 1899.

Liebermann, Pflüger's Arch., Bd. 43, S. 71.

Tichomi roff, Zeitschr. f. physiol. Chem., Bd. IX, S. 566. 